\title{
Blending in Advertisements for Events
}

\author{
Salsabila Bunga Sangsthita*, Rio Rini Diah Moehkardi \\ Universitas Gadjah Mada, Indonesia \\ *Email: salsabila.bunga991@gmail.com
}

\begin{abstract}
A B S T R A C T
Blending is often used in copywriting since the construction of the new words in blending is eye-catching. This paper investigates how blends are constructed in advertisements for events. The data for the research were obtained from advertisements for events held in Yogyakarta from 2014 to 2017. The data were analyzed using Hosseinzadeh's (2014) classification to determine the type of blends by reconstructing them and which type the most frequently used. The results show that 50 blends were found in the advertisements. Blends belonging to Types 1, 2, 3, 5 were used almost equally frequently, i.e., $22 \%, 20 \%, 20 \%, 28 \%$ respectively. Only two Type 4 blends (4\%) were found and Types 6 and 7 blends were not found at all. However, three new blends were found (6\%).
\end{abstract}

Keywords: Advertisement, Blending, Morphology, Word Formation.

\section{INTRODUCTION}

Language plays a great role in our civilization since it is the prime device for individuals to interact with each other. As a means of communication, individuals' attitude and feelings can be understood by others because they automatically use language. Basically, communication depends on the sender (speaker) and the recipient or receiver (listener or audience).

One of the uses of language is to persuade potential customers to purchase some of the particular products or services so that the companies can reach clients and/or customers. Customers usually buy those products based on what the companies offer. By using such persuasive way of communication, companies are directing their prospective customers to buy their best goods through advertisements. In connection with mass media, advertising is expected to reach a certain targeted profit. To make the advertisements catch the customers' interest, language as mass-communication is used. It can be seen on the catchy tagline and/or the creativity of the use of word formations to convey convincing ideas to the customers.

To make attractive contents of advertisements, language is used in such a way to make the advertisements attract the targeted audience. One of the focal points in advertisement is the name of the products. To make the products attract audience, producers often create names following how words, in general, are created or formed.

There have been a number of studies on the language used in advertisements. Samaru-Charles (2001) investigated rule-breaking in advertising language. She examined a range of advertisements in French and English, from different genres of magazines. She found that print advertisements do not disregard all conventions. No linguistic conventions were broken as breaking such conventions, she argued, would make them "sound extremely ungrammatical, unprofessional and lacking in finesse, which would be to their detriment. It is also partly because this type of rule-breaking would not aid the advertisement in drawing the reader directly back to the product" (p.25). Only rules and conventions affecting the 
reference to the products were broken. This was designed to give more focus on the products being advertised. She also argued that "This pattern of rule-breaking then is very valuable and beneficial to the realm of advertising as it helps advertisers achieve their goal of marketing a product as one that is desirable" (p. 25).

Another study by Kalima (2007) examined word formation processes in the game Dawn of War. The study focuses on the words that were used in the conversations among gamers, not the game's terms. 366 terms were found and categorized into 10 classes of word formation processes, i.e., acronyms, clips, alliterations, multiple processes, derivations, coinages, conversions, blends, and loans. The study also revealed that the most common word formation processes are acronyms (38.3\%) and clips (37.7\%). Kalima (2007) argued that this is slightly different from "normal" language use where "derivation, compounding and borrowing are much more dominant processes and clipping and acronyms are more restricted to specific areas of language use" (p.) 14.

Another study of advertisement Lusekelo (2010) investigated the relationship between the choice of the vocabularies, their morphology and phonological modifications and the anticipated meanings in the language of commercial advertisements in Tanzanian Swahili newspapers. A total of 138 commercial advertisements were collected and analyzed to find out the morphological and stylistic features available in these advertisements that lead to pragmatic purposes of the advertisements. The results showed that a lot of English words were used in the advertisements. Some of these load words were morphologically naturalized into Swahili and some others did not undergo any morphological change. Lusekelo (2010) argued that "there is a link between the designed morphology of the words and the interpretation captured, at least in the language of commercials."

Word formation processes have also been studied by Masithoh (2014). She focused on the word formation processes involved in the menu names at a restaurant. The data include 62 menu names found in the restaurant. The results showed that the names in the menu were created through the processes of compounding (10), derivation, inflection, acronym, blending, coinage, borrowing, clipping, reduplication and conversion.

Unlike the previous studies, Setyowati (2015) examined blends in the brands of snacks and beverages. The data were brands of snacks and beverages available in supermarkets in Yogyakarta. The data were analyzed using the theory proposed by Plag (2003). It was found that 25 blends were used in the brands of snack and beverages under study. The most common blends were formed by clipping and blending the first parts of two words (36\%). Another common method is clipping and blending the first and last part of two words (28\%).

Similar to Setyowati, the present study also investigates blends in English. It focuses on blends used in advertisements for events happening in Yogyakarta in 2014-2017. More specifically, it examines the morphological formation processes of the blends.

\section{THEORETICAL FRAMEWORK}

Word formation is one way of creating a new word. Plag (2003, p. 13) defines wordformation as "the ways in which new complex words are built on the basis of other words or morphemes which may have some consequences of such new definitions." There are at least six common word formation processes: acronym, abbreviation, backformation, compounding, clipping and blending (Plag, 2003).

Blending is a merger of two or more words where at least one of them has been shortened. The shortening can be a simple omission of a part of one particular word or it can be a result of overlapping sounds or letters (Algeo, 1977: 47-64). Moreover, according to Gries (2004), blending involves the coinage of a new lexeme by fusing parts of at least two other source words of which either one is shortened in the fusion and/or where there is some form of phonemic overlap of the source words. Blending is usually made to form new single meanings from two or more different meaning words.

Algeo (1977, pp. 47-64) classifies blending into three types based on how they are formed. 
1. Phonemic Overlap: a syllable or part of a syllable is shared between two words.

2. Clipping: the shortening of two words and then compounding them which reduces the longer forms; the lexeme is shortened, usually removing the end of the word, sometimes in the beginning, or both beginning and ending together (Crystal, 2003, p. 1). There are four types of clipping:

a) Back clipping in which the beginning is retained such as ad (advertisement), doc (doctor), exam (examination).

b) Fore-clipping that retains the final part, for example: chute (parachute), roach (cockroach), phone (telephone).

c) Middle clipping where the middle of the word is retained, for instance: flu (influenza), fridge (refrigerator), tec (detective) .

d) Complex clipping where one part of the original compound remains intact such as: cablegram (cable telegram), op art (optical art), org-man (organization man)

3. Phonemic Overlap and Clipping: shortening of two words to a shared syllable and then compounding. Example: autobydography (autobiography by dog), dog's autobiography; ambisextrous (ambidextrous sex), a nickname of a person who is very good at a sexual intercourse.

Clipping and blending are actually inseparable since the blending process usually requires clipping techniques. These types of word formations are fancied by those who are dealing with language as means of creativity.

Following Hosseinzadeh (2014), the term 'bit' and/or 'part' is here used to refer to the components of a word in blending process since there is no consistency in separating the word. To some data where the component words are not stated, the context in the posters will be used to find out the original component words. Some data whose meanings do not reflect the original component words were also analyzed.
Extending Algeo's (1977) classification, Hosseinzadeh (2014) classifies blends into seven types. Type 1 includes blends created using the first bit of the first word and the last bit of the second one (e.g., framily from friend and family). Belonging to Type 2 are blends that keep the whole part of the first word and a bit of the last part of the second word (e.g., Jazzercise from Jazz and exercise). Type 3 include blends that keep some parts of the first word and the whole of the second one (e.g., Eurasia from Europe and Asia). Type 4 are blends that are created by using the first parts of two words (e.g., avgas from aviation and gasoline). Belonging to Type 5 are blends with overlapping where usually the final part of the first word overlaps the second word (e.g., slanguage from slang and language). Type 6 consist of multiple sounds from the two component words blended, mostly preserving the sounds' order (e.g., daisy from day's and eye). Type 7 are composed of blends that are created by using the last parts of both words (e.g., podcasting from ipod and broadcasting). This classification was adopted for data analysis.

\section{METHODS}

The data sources for the present research were advertisements for events found in Yogyakarta in 2014-2017. The advertisements were found in billboards and/or posters with blends in them as headlines. The billboards and the posters were found offline on the streets in Yogyakarta and also online on social media.

The data were analyzed both qualitatively and quantitatively by reconstructing the words to find out their original components and then the blending process was analyzed and later the data were categorized into types of blends following Hosseinzadeh (2014). The frequency of blends was also observed.

\section{RESULTS AND DISCUSSION}

Based upon the data collected from the advertisements for events happening in the city of Yogyakarta from the year 2014 to 2017, altogether 50 blends were found. They were classified according to Hosseinzadeh's (2014) classification. Table 1 below shows the frequency and distribution of blends in the advertisements. 
Table 1. Frequency and distribution of blends in event advertisements

\begin{tabular}{rlrr}
\hline No. & Blend & \multicolumn{1}{c}{ Freq. } & \multicolumn{2}{c}{$\%$} \\
\hline 1 & Type 1 & 11 & 22 \\
\hline 2 & Type 2 & 10 & 20 \\
\hline 3 & Type 3 & 10 & 20 \\
\hline 4 & Type 4 & 2 & 4 \\
\hline 5 & Type 5 & 14 & 28 \\
\hline 6 & Other & 3 & 6 \\
\hline & Total & 50 & 100 \\
\hline
\end{tabular}

The table shows that Type 5 blends that are constructed by the overlapping of two words were used slightly more frequently (28\%) than Types 1 , 2 or 3 blends in the advertisements. This is somewhat surprising because there are more blends created using the rule of overlapping which is rather more difficult to be constructed compared to those which are made by clipping. The difficulties can be found in how the writer had to dig up word combinations that will be blended which have same parts - it can be in the form of the sound or letter - so that they can overlap each other.

The second most frequent use is the first type (22\%), the one that is formed using the first bit of the first word and the last bit of the second one, followed by the second type blends (20\%) which keep the whole part of the first word and a bit of the last part of the second word and the third type blends (also 20\%) that keep some parts of the first word and keep the whole of the second one. Far fewer than Types 1, 2, 3 and 5 blends are those belonging to Type 4 (4\%) and new blends (6\%) that do not belong to any type identified by Hosseinzadeh (2014). The following sub-sections discuss in detail each of the blend types found in the advertisements.

\section{Type 1 Blends}

Belonging to this type are blends that are created using the first bit of the first word and the last bit of the second one. 11 blends were found in the data. They are Fooshion, Exploraphoria, Psycret Admirer, Ecopreneurship, Instrumantic,
Sociophoria, actpression, Robelloween, Ecovolution, Weastfouria, and Broadmosphere. Discussed below are the formation of three blends Fooshion, Robelloween, and Weastfouria.

Fooshion, a blend from two words, food and fashion, omit the last consonant letter in the first word food (letter $d$ ) and also omit the first two letters from a pair of consonant and vowel in the word fashion (the letters $f$ and $a$ ). Although this blend keeps the original meaning of the original words, it can be easily associated with the term fusion as it is a mixture between food and fashion exhibition.

The original words of Robelloween are difficult to trace. However, from the poster advertisement, it could be inferred that the blend comes from the words Roaster, Bear, and Halloween. Actually, Roaster and Bear is the name of the restaurant in which the event was held. Robelloween is constructed by back-clipping the first two words, Roaster and Bear, and omitting the first two letters (consonant and vowel $h a$ ) in the word Halloween.

Weastfouria is formed from West-East, Four, and Euphoria since it is a collaborative event involving Japanese culture representing the East and English culture representing by the West. There were Japanese-culture related contests such as manga, rudoku, and kana as well as Englishculture storytelling and speech contests. The word four, however, was used probably because the event planner was Public High School 4 (SMA Negeri 4) Yogyakarta. And euphoria is added to ensure the potential audience that the event would bring happiness.

\section{Type 2 Blends}

The type 2 blends are those that keep the whole part of the first word and a bit of the last part of the second word. Ten names of events were found in the advertisements. They are Lenspired, Sciensation, Soundsations, Electronicoustic, Bearentine, Foodgraph, Earthernity, Folksphere and Sharepreneur. Below are three blends illustrating the use of this type.

The word Lenspired can be seen as a derivation of inspired and is a good example of a description of a photography event since the 
single vowel $i$ in its original word is replaced by a four-letter word lens. It has the exact same construction with the term Soundsations where it keeps the whole word of the first part and clipped the fore syllable of the second one: Lens + Imspired. The formation of the blend Bearentine involves a process in which the first word (bear) is written in full and the first three letters ( $\mathrm{val}$ ) of the second word is omitted, thus producing Bear+ Valentine. In the case of Earthernity, the first word earth is fully maintained while the first two letters (et) of the second word, eternity, is foreclipped so that what remains is ernity. Earth + eternity.

\section{Type 3 Blends}

Ten blends were found belonging to Type 3: Pharmadays, Psycurious, Thursdance, Wednesdance, Magnifisound, Dedicart, Akulturaksi, Francinema, Pameat and Edufair. These blends keep some part of the first word and the whole of the second one.

Thursdance and Wednesdance refer to a dance event held every Thursday and Wednesday; They are formed from the words Thursday and Wednesday + Dance, where the back part of the first word is removed but the second word is kept in full. The term Psycurious has an exactly similar construction where psychology, as the first word, is clipped so that it only maintains the first syllable and keeps the second word untouched: Psy ology + curious. Pameat is a food event in a hotel which serves varieties of meat. The blend is formed from two words, Parade and Meat which grammatically is not precise from the view of word order. It should have been Meat Parade instead. However, to associate with an Indonesian word pamit the advertiser then formed those words in such a way so that it can be comprehended as a familiar Indonesian word pamit.

\section{Type 4 Blends}

Type 4 blends are created by using the first parts of two words. Only two names of events were found in the advertisements. They are Ecofest, and Crenation.
The event Ecofest is actually an economics festival that is written by combining the words economics and festival into a blend in which the last two syllables in the first word and the last four letters in the second word (ival) are backclipped.

Crenation is formed from two words creativity and nationalism. This process involves the clipping of the last part of the first and second words (ativity and alism) so that they only maintain the first part of both words: creaty + nationalism.

\section{Type 5 Blends}

Type 5 blends are constructed by shortening two words to shared syllables. 14 blends were found in the advertisements. They are Imaginightion, Voltension, Shopartholic, Artourism, Salebration, Relationshit, Communitea, Supersemarch, Jogjacarta, Crafootik, Congraduation, Guitarun, Atlightic, and Marketaste.

In the blend Guitarun there is only a single $r$ included in the blend as the letter $r$ in the last of the first word and the letter $r$ in the first part of the second word overlap each other: Guita $+\underline{\text { Run}}$. The blend is possibly formed to associate the event with a local Javanese term gitaran, which actually is an activity when a person plays a guitar. It is possible that the lexeme run is added because the tagline is ngeblues sambil lari, literally meaning "playing blues songs while running".

The blend Atlightic is created from an overlapping similar sound of let in the words athletic and light. The word light is fused in the word athletic as a replacement of the phoneme let because it is actually a sports event whose tagline is "Spark Your Action". The term spark definitely has an association with the term light. Actually, this formation is violating the English sound rules because of the local pronunciation which considers / $1 \Lambda$ It/ as having a similar pronunciation to let.

\section{Other Blends}

There are three blends that do not belong to any type of blends identified by Hosseinzadeh (2014). They are Bandfest, WARMfest, and 
Refoodlution. In the case of Bandfest, there is no type of blend which keeps the first word whole and back-clipped the second one.

WARMfest, however, is an acronym of World Animal Resound Music Festival, which is a music event created by the Faculty of Veterinary Science, Universitas Gadjah Mada. Therefore, it only maintains the first four letters in order to construct the word warm and it clearly does not belong to any blend types.

\section{CONCLUSION}

Overall, out of the seven types of blends identified by Hosseinzadeh (2014), only five types were found in the data. The five types are the blends created by using the first bit of the first word and the last bit of the second one (Type 1), the blends which keep the whole part of the first word and the last part of the second word (Type 2), the blends which keep some parts of the first word and the whole of the second one (Type 3), the blends constructed by the first parts of two words (Type 4) and overlapping (Type 5). The other two types which are not found in the name of events in Yogyakarta were the blends which are constructed by the last parts of two words (Type 6) and the blends that have multiple sounds from two blended words (Type 7).

It can be concluded that there seems to be no dominant types of blending in the creation event names even though blends created through overlapping is slightly more common than the other methods. However, this is interesting as overlapping is harder to form compared to the other types which are simply formed by combining two or more clipped words. It can be argued that non-native advertisers seem to have the capability to create new, crative English blends even though they sometimes disregard the English sound patterns and word classes. The level of creativity in Yogyakarta is impressive based on how they form new words for event names in a foreign language.

\section{REFERENCES}

Algeo, J. (1977). Blends, A stuctural and systemic view. American Speech 52(1/2), 47-64.
Crystal, D. (2003). A dictionary of linguistics and phonetics. Oxford: Blackwell Publishing.

Gries, S. T. H. (2004). Shouldn't It Be Breakfunch? A Quantative Analysis of Blend Structure in English.

Hosseinzadeh, N. M. (2014). New blends in English language. International Journal of English Language and Linguistics Research 2(2), 15-26.

Kalima, J. (2007). Word Formation on Internet Gaming Forums. Unpublished undergraduate thesis. Jyväskylä: University of Jyväskylä. Retrieved from https://jyx.jyu.fi/ bitstream/handle/123456789/18948/Kalima_ Juhamatti_kandi.pdf.

Lusekelo, A. (2010). Morphology-pragmatics interface: The case of the Tanzanian commercials in Swahili newspapers. Afrikanistik Aegyptologie Online. Retrieved from https://www.afrikanistik-aegyptologieonline.de/archiv/2010/2711.

Masithoh, T. (2014). Word formation process at Pazzo Pancake menu names in Kudus Extention Mall. Lantern 3(2), 1-8. Retrieved from https://ejournal3.undip.ac.id/ index.php/engliterature/article/view/5274/ 5079.

Plag, I. (2003) Word-formation in English. Cambridge: Cambridge University Press.

Samaru-Charles, L. (2001). Rule-breaking in the language of advertising. Unpublished undergraduate thesis. Swathmore, P.A.: Swathmore College. Retrieved from https://scholarship.tricolib.brynmawr.edu/bi tstream/handle/10066/10849/SamaruCharles_thesis_2002.pdf?sequence $=1$ \&isAllo wed $=y$.

Setyowati, R. (2015). Prosodic morphological analysis on blends used as brand of snacks and beverages. Unpublished undergraduate thesis. Yogyakarta: Universitas Gadjah Mada. 